\title{
Lecturas decoloniales de la poesía mapuche de María Teresa Panchillo, Chile
}

\section{Decolonial readings of mapuche poetry by María Teresa Panchillo, Chile}

\author{
Damsi Figueroa Verdugo* Noelia Figueroa Burdiles**
}

\begin{abstract}
Resumen: La poesía de María Teresa Panchillo es coherente con el discurso político histórico del pueblo mapuche, desarrolla a su vez una escritura que persigue fidelidad a las estructuras y protocolos de la tradición oral mapuche. Los contenidos de su poesía, remiten principalmente a los procesos de recuperación de tierras, y a las estrategias que permiten que estos procesos tengan un impacto efectivo en el Küme mongen o buen vivir de las comunidades mapuche. En su poética, la palabra compromete la valoración pragmática del mapudungun como lengua escrita que tiene que ser leída en clave decolonial. Este ensayo explora la poesía de Panchillo en tanto exposición del discurso autonomista mapuche histórico, a la vez como mecanismo de comunicación intra e intercultural de los aspectos estructurales y valóricos de lengua mapuche, que sostienen de acuerdo a la poética de Panchillo, la vida en territorio mapuche.
\end{abstract}

Palabras claves: Poesía mapuche, autonomía, territorio, lectura decolonial

\begin{abstract}
Mapuche poetry by María Teresa Panchillo is coherent with the politicalhistorical discourse Mapuche people, in turn develops a writing that pursues a fidelity to the structures and protocols of the Mapuche oral tradition. The contents of his poetry refer mainly to reclamation processes the land and to the strategies that allow these processes to have an effective impact on the Küme mongen or Buen Vivir of the Mapuche communities. In his poetics, the word implicate the mapudungun's pragmatic appreciation as a written language that must be read as a decolonial code. This essay explores the poetry of Panchillo as an exposition of the historic Mapuche autonomist discourse, at the same time as a mechanism of intra and intercultural communication of the structural and value aspects of the Mapuche language, which, according to Panchillo's poetics, sustain life in the territory Mapuche.
\end{abstract}

Keywords: Poetry Mapuche, autonomy, territory, decolonial Reading

Recibido: 2 agosto 2017

Publicado: 13 octubre 2017

* Doctora en literatura hispanomericana, Universidad de Concepción, Chile, damsifigueroa@udec.cl

** Magister investigación social, Universidad de Concepción, Chile, noeliafigueroa@udec.cl 


\section{Poesía mapuche y giro decolonial}

La poesía mapuche actual ingresa tomándose el canon de la literatura chilena; hoy es posible reconocer en los estudios de poesía mapuche un sólido segmento de trabajos académicos que derivan de una atención especial a esta producción literaria, y que se instala como signo de una transformación cultural profunda en la sociedad chilena, global y sobre todo en el plano de las relaciones interculturales: la literatura mapuche es expresión de un diálogo sin precedentes en nuestra historia literaria y sociocultural. Ello nos obliga a profundizar en la comprensión de la cultura y la epistemología mapuche, que encuentra sus bases en el mapuche kimün y el mapuche rakizuam, entendidos, en este ensayo, como el pensamiento mapuche de origen ancestral y el pensamiento mapuche contemporáneo, respectivamente.

Las lecturas posibles de esta producción literaria deben nutrirse de otras producciones que forman parte de un mismo fenómeno de recuperación y fortalecimiento de la historia, la lengua y la cultura mapuche: Investigaciones linguísticas, históricas, recopilación de testimonios, de expresiones etnoliterarias, documentos que profundizan en el pensamiento mapuche basados en la diferenciación territorial y que codifican en un nuevo lenguaje intercultural el pensamiento de los ancianos y kimche, ngempin, lonkos que están pensando el ser y el estar del pueblo mapuche en toda su diversidad y complejidad histórica. Las y los poetas mapuche han demostrado que son portadores de este diálogo intercultural; usando como lengua poética el mapudungun; trascendiendo las conceptualizaciones subalternas que las enmarcan dentro del pensamiento abismal (Santos, 2013), que desconoce como conocimiento válido aquel conocimiento que la ciencia no puede explicar con sus propios métodos; comprendiendo que la ciencia occidental y su epistemología fue construida a partir de las necesidades de la dominación capitalista y colonial. Este pensamiento abismal, produce tendencias interpretativas generalizantes que limitan producciones rurales e indígenas, a una expresión de cierta "ingenuidad pastoril", cuando no revelan las tensiones con el capitalismo o la guerra o se anclan en tiempos remotos y mejores. No obstante ¿no es esta imaginación poética la que permite sostener la potencialidad de otras formas de vida, desde la perspectiva ontológica y epistemológica?; ¿cómo comprender estas formas de vida, que se expresan aunque sea fragmentariamente, en contextos hostiles de dominación mental y física que niegan permanentemente su existencia?; ¿estas resistencias que se han sostenido por siglos como permanentes procesos de recuperación y "re-existencia", no constituyen acaso una prueba de la magnitud de su poder frente al capitalismo y la modernidad?. Estas preguntas son las que conducen una lectura decolonial de la poesía de Panchillo, es decir, una lectura que intenta trascender el velo colonial con que el pensamiento moderno e incluso contemporáneo ha significado la producción cultural de otros pueblos, como estrategia permanente de dominación.

Esto no implica asociar la poesía de Panchillo a las necesidades del esencialismo epistemológico (Briones, 2007); sino se propone explorar sin pretensiones teóricas previas más que el giro decolonial, los valores que en la lengua mapuche sostienen la vida en resistencia y al mismo tiempo la potencialidad de la autonomía territorial, desde una 
perspectiva epistémica y ontológica, como su fuente de poder, es decir, como trascendencia de la subalternidad (Figueroa, 2012). Esto significa que la poesía de Panchillo es portadora de un conocimiento que será develado por el lector si es capaz de realizar una lectura decolonial que, si es posible conducirla, implicará cuestionar y trascender el pensamiento abismal propio, produciendo un diálogo donde el otro puede tener la razón y donde las respuestas a las preguntas que surjan de la lectura se orientan desde una perspectiva contrahegemónica. La adopción de esta perspectiva contra-hegemónica no es un proceso fácil; desde la interculturalidad crítica (Walsh, 2012), implica vencer las categorías racistas, subalternizadoras y de superioridad cultural propias del pensamiento moderno y que operan epistemológica y ontológicamente.

La poesía mapuche nos permite indagar y a la vez reconstruir una nueva imaginación de la historia donde las voces silenciadas de los vencidos, no así rendidos, llenen los vacíos de los relatos históricos que ha negado sistemáticamente un lugar a aquellas voces. De allí que la poesía mapuche de María Teresa Panchillo en este artículo es leída en clave decolonial, es decir, "la cuestión no pasa por si habla o no habla el subalterno o por si somos capaces de develar sus lenguajes o cosmovisiones para escapar de las representaciones habituales. El giro acá está dado por la adopción de nuevas lecturas de la realidad desde un caleidoscopio epistemológico, que debilite las estructuras de poder que están insertas en las formas coloniales/modernas de ver la (s) realidad (es)" (Figueroa, 2012,11). Desde la herida colonial del pueblo mapuche que continúa hasta hoy, María Teresa Panchillo conoce las palabras que le devuelven la fuerza para denunciar el despojo y perseverar en la autonomía, con el poder que fundamenta su lengua vernácula.

\section{La lengua poética de Panchillo}

La poesía mapuche de María Teresa Panchillo se escribe en coherencia con el discurso autonomista de carácter histórico (Betancour et al, 2014), desarrolla a su vez una escritura que persigue fidelidad a las estructuras y protocolos discursivos mapuche orales. Estos discursos tradicionales a los que nos referimos están presentes en las formas de comunicación intracultural que se practican en las comunidades hablantes del mapudugun, y al ingresar a la poesía mapuche escrita bajo la estructura de un collage etnolingüístico (Carrasco, 1996, 86): español-mapudungun, ingresan dejando huellas de su oralidad, inscritas en aspectos formales, que a la vez corresponden a los principios éticos sobre los que se basan los procesos comunicativos. Los aspectos estructurales y valóricos de los discursos tradicionales mapuche que se pueden observar en la poesía de Panchillo son: la identificación clara del hablante, definición clara del objetivo o de la función del encuentro, evaluación del estado en que se encuentran las personas que participan del encuentro, búsqueda común del equilibrio, bien estar espiritual, corporal del individuo y de todo su territorio (lo que nos recuerda la noción del "buen vivir" de los pueblos andinos), compromiso y despedida.

El estilo de la poesía de Panchillo, es auténtico, en el contexto de la poesía mapuche y de la poesía chilena en general. Su verso es siempre libre, la elipsis verbal y en general la ausencia de puntuación son características permanentes de su poesía, que adopta a través de 
estos recursos un estilo conversacional, que no coloquial. No posee intertextos ni remite a otros poetas chilenos ni latinoamericanos, no en su estilo ni en su lenguaje, pero si menciona un par de veces, a Neruda y a Ercilla, solo para explicar que su lenguaje es otro, que su vertiente literaria y la función de su poesía es otra: el arte de la palabra hablada por sus autoridades ancestrales: kimche, longko, machi, ngenpin, ulkantufe, weipife. Su única filiación posible, en cuanto ritmo, tono, estructura de los versos y estrofas, es la de los discursos mapuche tradicionales en mapudungun y los discursos políticos, de arenga ideológica, propios de los partidos políticos y movimientos de izquierda de los años 80 y de los actuales movimientos mapuche de recuperación territorial.

El mapudungun es la primera lengua, la lengua madre de María Teresa Panchillo, su uso es clave en su escritura poética. El grafemario utilizado por María Teresa Panchillo en sus textos corresponde al Alfabeto Raguileo. Este alfabeto fue creado por Anselmo Raguileo en 1982, profesor de lengua mapuche y licenciado en Química, quien participó en diversas instancias político organizacionales para la mantención y proyección del idioma mapuche. En Temuco trabajó junto al grupo de escritores del centro cultural Mapu Nuke, instándolos y capacitándolos para escribir en mapudungun ${ }^{1}$. "El alfabeto Raguileo se fundamenta en una posición de diferenciación y autonomía de la lengua mapuche en relación con el castellano, la lengua de la sociedad dominante" (Wittig, 2006, 8). Este alfabeto pretende anular la asimilación de sonidos del mapudungun al español que poseen los otros grafemarios como el Unificado y el Azumchefe.

La poesía de Panchillo circula casi exclusivamente en el contexto de la poesía mapuche actual, no ha sido estudiada ni valorada en términos de su complejidad estética intercultural, asumimos porque, su estilo no calza dentro de la poesía moderna; el sujeto de la enunciación no es un sujeto que se niega a sí mismo como lo es en la poesía de otros poetas mapuche como Jaime Huenún (2012), Cesar Cabello (2011) y Juan Wenuan (2014), sino un sujeto que se fortalece a través de un discurso reivindicativo, por lo tanto sus imágenes y construcciones aspiran a la comunicación de ideas claras y efectivas, su poesía tiene una función eminentemente socio-política. La lectura e interpretación de su poesía exige situarse en el contexto histórico y el horizonte cultural mapuche. Panchillo trabaja en la radio de Traiguén y junto a su propia casa en el campo, ha levantado una ruka donde enseña a niñas y niños mapudungun y practica la integridad del kimeltuwün, el sistema de educación tradicional mapuche. Comenzó a escribir, como ella misma señala, "gracias a la dictadura", cuando chilenos y mapuche se unieron en una causa común. Muy joven viajó a vivir a Santiago donde trabajó y estudió para graduarse de enseñanza media. En los años ochenta se vinculó a grupos de izquierda que se organizaban para defenderse y derrotar la dictadura militar. A principio de los años 90 regresó a Territorio Nagche, a la comunidad Juan Maika, la comunidad de su esposo, tal como dicta el az mapu, la ley mapuche y ahí comenzó a trabajar activamente en los procesos de recuperación territorial.

Los contenidos de su poesía, remiten a diversos aspectos de los procesos históricos mapuche, pero principalmente a aquellos contingentes relativos a los procesos de

\footnotetext{
${ }^{1}$ Según testimonio de la poeta mapuche Rayen Kuyeh entregado en Encuentro de poetas en Imperial, 2011.
} 
recuperación de tierras, y a las estrategias de organización política, económica y social que permiten que estos procesos tengan un impacto efectivo en el Küme mongen o buen vivir de las comunidades mapuche. Su poesía tiene un valor histórico, testimonial, y desde nuestro punto de vista altamente estético pues porta la fuerza, la vitalidad creativa de la lengua mapudungun. El español utilizado por Panchillo, es su segunda lengua, las marcas de esta condición lingüística aportan rasgos únicos a su escritura, dentro del contexto general de la poesía mapuche: uno de ellos, el más evidente es la ausencia repetida de la marca plural en los sustantivos. Su poesía exhorta permanentemente al lector no mapuche a tomar posición, mas está principalmente dirigida a lectores mapuche, con quienes comparte las visiones, sentidos, experiencias y proyecciones de sus ideas políticas, creencias espirituales y rasgos culturales en general.

\section{Canto de mujeres guerreras}

La demanda de tierras ha sido un proceso que ha marcado las relaciones entre el estado chileno y el pueblo mapuche durante todo el siglo XX hasta la actualidad. A principios del siglo XX, con el proceso de radicación tras la "pacificación de la Araucanía", comprendida por autores como Correa y Mella (2010) como la ocupación militar de la Araucanía y la usurpación territorial por parte del estado chileno, muchas comunidades mapuche, lafkenche, nagche y pehuenche iniciaron la demanda por sus tierras despojadas, a partir de los títulos de propiedad que les fueron entregados en tal proceso de radicación, que se extendió entre los años 1884 y 1929 (Bengoa, 2004). Estos títulos fueron conocidos con el nombre de "merced", cuyo nombre deriva de las leyes que desde 1866 y posteriores "establecieron que a los indígenas se les daría un título gratuito sobre las tierras que poseían" (op. cit, 336). Este proceso de titulación confinó al pueblo mapuche a unas quinientas mil hectáreas de un territorio original de diez millones (Aylwin, 2002, citado en Figueroa et al, 2005).

A lo largo del siglo $\mathrm{XX}$, organizaciones del pueblo mapuche propiciaron diversos espacios de negociación con las coaliciones políticas y gobiernos de turno (Foester y Montecinos, 1988; Marimán et al 2006), ocupando también puestos en el parlamento en la primera mitad del siglo. Para el proceso de reforma agraria, que se extendió entre los años 1962 y 1973 (Correa, Molina y Yáñez, 2005), si bien la demanda por la restitución de tierras mapuche fue acogida por los gobiernos de turno, al mismo tiempo fue comprendida en los términos asociativos y productivistas desde una perspectiva campesina y no mapuche (Correa y Mella, 2010). No obstante, en este proceso los mapuche de la Araucanía lograron que ciento cincuenta y dos mil cuatrocientas dieciséis hectáreas fueran expropiadas a su favor, estableciéndose asentamientos mapuche en las tierras recuperadas (Correa, Molina y Yáñez, 2005). Todo este proceso no estuvo exento de conflictos al interior y exterior de las comunidades, lo que quedó de manifiesto en la muerte y desaparición de muchos mapuche con el golpe militar, y el apoyo de algunos mapuche a dicho golpe (Mariman et al, 196198). La dictadura militar a partir de 1973, traería consigo un proceso de contra-reforma agraria, materializado en la destrucción de los asentamientos, expulsando a los mapuche de ellos, y en la revocación, remate y/o parcelación de las tierras expropiadas durante la 
reforma (Correa, Molina y Yáñez, 2005), como por ejemplo, la revocación del proceso de expropiación del emblemático fundo Temucuicui en Ercilla y el fundo Pidenco en Lumaco, que fueron nuevamente expropiados a los mapuche y devueltos a sus antiguos propietarios (op. cit, 257, 259). Este nuevo proceso de expropiación de tierras mapuche abrió paso a la nueva propiedad forestal principalmente en la provincia de Malleco y en la provincia de Arauco, que fue potenciada a partir de 1974, a través de la creación del decreto de fomento forestal 701, que subvencionaba la plantación de especies exóticas en un 75\%. Este proceso se da en paralelo a la división definitiva de comunidades mapuche a través de la titulación individual (decreto 2568 de 1979, citado en Mariman et al 2006, 234).

Los procesos de diálogo entre el pueblo mapuche y el estado chileno se retomaron a partir de la discusión de la ley indígena a principios de los años 90, con la restitución del sistema de elecciones populares. En esos años se creó una Comisión conocida por su sigla CEPI que tendría la responsabilidad de dialogar con diferentes referentes de los pueblos indígenas de Chile y crear una ley destinada a dar cuenta de sus principales demandas. Al mismo, tiempo se levantaba el Consejo de Todas las Tierras, con la conmemoración de los " "500 años' en 1992, con sus recuperaciones simbólicas de tierras, sus movilizaciones, la creación de una bandera nacional mapuche, su rechazo a las instituciones (...) y el posicionamiento internacional de la demanda por los derechos mapuche" (Marimán et al, 241). La promulgación de la ley indígena en 1994, que concitó en los inicios de su formulación a una parte importante del movimiento mapuche, no obstante, no fue capaz de proteger los derechos a tierras y territorio en un contexto de globalización e inversión transnacional, lo que quedó de manifiesto con la construcción de dos centrales hidroeléctricas en territorio pehuenche de Alto Bio Bio (Correa y Mella, 2010).

Las organizaciones mapuche de entonces confiaron en que esta nueva ley proyectaría una serie de cambios importantes, entre ellos la restitución de tierras y la instauración de una nueva dinámica en las relaciones del Estado chileno con el pueblo mapuche. Panchillo deja testimonio de la inconformidad con la Nueva Ley Indígena promulgada en 1993: "Ustedes que se callaron/cuando tuvieron palabras/ (...) / ¿Qué van a hacer?/¡Qué van a decir/ cuando se derogue el 2568?" (poema "Ustedes", Panchillo, 1999, 57); "Me dispararon desde la moneda/con una bala de calibre 2.568/ (...) Por que soy mapuche-pueblo/ No me matarán con decretos/ Ni con balas/ De calibre recién inventado. / (...) Cuando suene/ El kullkull y la xuxuka/ Recuperaré la sangre/ de mis óvulos florecientes/ Seguiré procreando hijos indomables./ (...) Bajaré de los volcanes/ armada de canciones y palabras nuevas/ porque en quinientos años/ No han podido/ Dispararme en la boca." (poema "Calibre 2.568", Panchillo, 2006, 81). Y como es ley en la poesía de Panchillo, no hay rendimiento ni decaimiento posible, frente a la implantación de esta nueva ley injusta, la palabra seguirá levantándose y cada vez con más fuerza, para seguir denunciando cómo el mecanismo establecido para la restitución de tierras, a través de la compra de tierras por parte del Estado, no logró dar cuenta de las expectativas de las comunidades, dado que sus derechos territoriales de agua, de subsuelo, que no estaban cubiertos por la ley, quedaban expuestos a los proyectos económicos de la expansión neoliberal (Mariman et al 2006). En este contexto, comunidades de la comuna de Lumaco en la provincia de Malleco comenzaron a 
ocupar y a reocupar predios de empresas forestales (Correa y Mella, 2010), desembocando en lo que podría llamarse un nuevo ciclo en las relaciones del pueblo mapuche con el estado: en el año 1997 se inicia un nuevo ciclo de movilizaciones que desembocará en lo que actualmente se denomina 'conflicto mapuche':

"En octubre de 1997 las comunidades mapuche de Pichilcoyan y PilinMapu, en la comuna de Lumaco, ocuparon el fundo Pidenco de la forestal Bosques Arauco, a las pocas horas se produjo un enfrentamiento con carabineros y fueron desalojados. Dos meses más tarde, el $1^{\circ}$ de diciembre de 1997 , en el mismo sector fueron quemados tres camiones de la empresa forestal antes mencionada, dando inicio a un conflicto se ramificó en distintas zonas del territorio mapuche" (Mariman et al, 244).

El desalojo del fundo Pidenco resultó altamente violento, con 37 personas mapuche detenidas (Correa y Mella, 2010). El que fuera Lumaco el lugar del nuevo levantamiento según estos autores no es casual, pues se configura como "el paradigma de la ocupación territorial por parte del invasor" (218), que ahora se materializaba en las empresas forestales.

\section{Weycafe}

Hoy tengo las palabras

De tu arenga weycafe

Tengo la noche más helada

En PIZEÑKO, en los cerros del fundo.

Tengo la comisaría y un parte vencido

De la camioneta

Tengo los bosques de pinos y de eucaliptus

En las orillas de las carreteras

En las orillas de los ríos

Transformándonos,

procesando como una máquina

El clima del Malleco.

Pasamos las sequías

Nevazones e inundaciones

Hoy llueve a todo sol

Y leo un poema de Elikura,

En el punto exacto del proceso

Dos hermanos en la fiscalía miliar.

La transformación de la zona

En un clima tropical

Lo que mañana será desierto

Si continúa así.

La negociación con la fiscalía 
No es fácil dijo un weycafe,

... y la machi dijo:

Ya no había agua en el pozo

Con esta lluvia se recuperó.

En definitiva

Tengo la noche de lucha

La noche de los valientes

De los sin miedos.

...y esta no es la recuperación

De la tierra del fundo

Es la recuperación TERRITORIAL

Dijo: otro Weycafe.

Tengo las fuerzas y las palabras

De los Weycafe

Tengo hasta el llanto de los hijos

Que nacen en un amanecer

De Diciembre en Lumako.

Ropitas...no hay...

Para el niño que nace dijo

Y eran dos niñas mellizas

...jla pobreza no da más!...

¡amuyiñ, amuyiñ!...

Vamos, vamos...jMARI CI WEW!

Gritó el lamien

¡no más aspirina de la CONADI!

No más proyectos de experimentos

Dijeron los weycafe.

Hoy esperamos cualquier cosa en Lumako...

Enfrentamientos, cárceles o muertes

Pero en definitiva esperamos la TIERRA.

Lumako, Noviembre- Diciembre de 1997 (Panchillo, 1999, 62-63)

La poesía de María Teresa Panchillo entrega el testimonio directo del origen de la reconfiguración territorial mapuche en el nuevo escenario político y económico del país. Y dentro de este relato surge una poética centrada en codificar y transmitir a través de un nuevo lenguaje literario la auténtica forma de ser, de vivir y de sentir de una cultura en resistencia. Su discurso poético reafirma de manera estratégica los dos principios sobre los que se sostiene la lucha mapuche por la recuperación de tierras: el histórico y el espiritual. El histórico alude al territorio y el espiritual a la tierra como madre, a la Mapu Nuke. Para los mapuche ambas son realidades inseparables. Los poemas de Panchillo evocan con fuerza los distintos momentos claves de la historia mapuche: la guerra de la Araucanía, la 
guerra de ocupación de las tierras mapuche por parte del estado chileno y la actual guerra de expoliación de los recursos naturales por parte de las empresas transnacionales (Paredes Pinda, 2012). Dar continuidad histórica, de ya más de 500 años, a la lucha de resistencia mapuche es el objetivo de las permanentes evocaciones a Lautaro, figura cúlmine de la inteligencia militar mapuche, cuya memoria heroica ha sido poetizada incansablemente por poetas chilenos y de toda Latinoamérica ${ }^{2}$. Sin embargo, estas evocaciones heroicas a la figura de Lautaro no alcanzan el profundo, vital y sobre todo actual sentido que tienen en los poemas de Panchillo:

\section{Lefxaru (Lautaro)}

A ti te digo

Si puedes escuchar en la profundidad de la noche.

Estamos descubriendo las huellas que dejaste

Marcadas en la tierra

En las aguas

En los árboles.

EN TODA LA NATURALEZA QUE NOS PERTENCE.

Y lucharemos como tú

Sabemos que para ti

Solo la lucha tiene sentido

No una poesía infantil

Escrita en un momento emocionante

Ni una promesa en los días dolorosos

¿Llegará la primavera para Chile

Volarán las águilas veloces por el mundo

Llevando mensaje de victoria

A los hijos de la tierra?

Sabrás Lefxaru

Que las promesas estaban destinadas a cumplirse

¿Tendrá sentido la poesía infantil

Escrita con rabia en forma de panfleto?

No nos vencerán Lefxaru

Entonces, cantaremos tu nombre

Tu figura heorica

Los niños de subrayarán en la historia. (Panchillo, 2006, 71-72)

\footnotetext{
${ }^{2}$ Pablo Neruda erigió en el poema La educación del cacique la figura de Lautaro como "nuestro padre", por lo tanto como héroe de todos chilenos, adoptando así, la idea de la nación mapuche heroica en la base de la construcción mítica de la raza chilena: Elástico y azul fue nuestro padre... . Junto a Lautaro, Caupolicán, cuya figura, no menos descomunal, sin embargo, no ha corrido la misma suerte, en tanto ha servido para representar la derrota, sino el sometimiento de la raza y aún de la misma naturaleza, como expresan sendos poemas titulados Caupolicán de Rubén Darío y de Santos Chocano.
} 
La poesía de Panchillo se sitúa siempre en el tiempo presente de lucha y resistencia. Panchillo será, junto a la poeta Rayen Kuyeh, en el contexto de la poesía mapuche, las voces que se alzan de manera más clara y directa frente a los invasores de todos los tiempos. La poesía de Panchillo es una poesía siempre actual, poesía guerrera por excelencia, de tono siempre triunfante, en ella no se deja entrever jamás el desaliento ni el delirio, como sucede en Cantos de guerreros/Weichapeyuchi ül (2012) ${ }^{3}$, cuyos tonos, atmósferas y sensaciones nos hablan del miedo y de la confusión, del dolor que congela la sangre y apaga la voz de los ulkantufe, como leemos en el poema "Urgente" de Huirimilla o en "Le sacaron la piel" de Leonel Lienlaf, y en tantos otros que denuncian los terrores de la(s) guerra(s), mas no constituyen, como en Panchillo, una "arenga de levantamiento general" dirigida en tiempo presente a los grupos de mapuche organizados en los procesos de recuperación territorial, tan claramente como puede apreciarse en el siguiente poema:

\section{Ñi Guyvgenoam}

Mawkvlechi ñapvz mew

Zoy tuy newen zevñ pvle pu che

Aynetufilu reke chi axev

Ukvlla tuy

Xarilonkotuy vllcha ke zomo

Kelluntukualu weycham mew....

En plena lluvia de nieve

Tomaron más fuerzas

La gente por las cordilleras

Desafiando el frío

Se puso la vkvlla

Su trarilogko las

Mujeres más jóvenes

Para sumarse a la lucha...

Chvwvz chvwvz tuy ñi wixvwe chi weychafe

Piwke mew kvllvfi

Fente ñi kuxantun

ZUGUY...

Kom bayaygvn

Ixofill xalka mew PI

IÑCHIÑ EM KAY...

Re wvño mew xakatuayiñ

Re kura mew mvten wixvwtuafiyiñ

\footnotetext{
${ }^{3}$ Título del libro compilado y editado por el poeta Huirimilla, donde no incluye poemas de María Teresa
} Panchillo. Huirimilla (2012). 
Giró, giró el wixvwe el weichafe

Le dio en el corazón

Le dolió tanto

Que se pronunció

DICIENDO...

Morirán todos, les pondremos DINAMITAS!

Y nosotros QUÉ...

Le pondremos cartuchos a los wvños?

Y piedras nomás a los wixvwe...

Rupaley antv

Amuley weychan

Mutual ñi mapa

Tami pu choyvn GVNEMAPUN

Azutupe ga ñi wizvel chi mapa

Pile tami gillatun

Ragiñ wenu kuche

Ragiñ wenu fvcha

Kiñe lukutun mew

Mari chi wew!

Piyay ñi wirar kiñe puliwen

Kompvle mapu tami pu che...

Pasan los días y continúa la lucha

Por recuperar las tierras ancestrales

Tus seres que creaste GVNEMAPUN

Si los ancianos y ancianas

Piden en un arrodillar

En un Gvillatun

Desde lo más alto del cosmos

Que se reordene la tierra

Que construiste como la alfarería

Más perfecta

Podrán entonces gritar

Un gran ¡MARI CHI WEW!

En algún amanecer

Por todas partes tus hijos Mapuche... (Panchillo, 2009, 148-149)

Mapuche Kimün, sabiduría mapuche, expresado en los tópicos de la poesía de María Teresa Panchillo

La espiritualidad mapuche, feyentun, ingresa en la poesía de Panchillo a través del mapudungun. En diversos poemas Panchillo nombra en mayúscula a GENVMAPU, máximo espíritu sostenedor de la vida en el Mapu. Una de las formas en que el 
mapudungun ingresa como lengua poética es a través de los textos de carácter religioso; poemas que se construyen siguiendo la estructura del Yeyipun, un especial tipo de rogativa; forma de comunicación con las divinidades mapuche que se realiza siempre que se agradece y se encomienda alguna acción importante que será desempeñada por alguna colectividad. El Yeyipun sigue una estructura más o menos fija: en primer lugar, se saluda a la familia originaria que habita el wenü тари, o tierra de arriba, y luego se saludan las fuerzas o energías circundantes; dependiendo del lugar donde los oradores se sitúen, y el contexto en que se realice el yeyipun, éste se desarrollará con algunas variaciones. La poesía mapuche actual busca establecer una relación de identidad y continuidad con las formas discursivas y tipos textuales de la tradición oral.

Uno de los procedimientos más recurrentes es la introducción de fórmulas ceremoniales rituales que abren y/o cierran los proyectos a modo de macro texto, y que orientan el sentido dialógico del conjunto textual al acentuar la diferenciación de los sujetos que forman parte de la relación cultural. Poemarios como Arco de interrogaciones de Bernardo Colipán, Oratorio al Señor de Pucatrihue de César Millahueique, Mapurbe de David Aniñir, entre otros y los proyectos musicales de Pirülonko, son algunos casos referenciales de este proceso (Betancour et al, 2014, 70).

La espiritualidad y el discurso de carácter político se unen en la visión colectiva de todo un pueblo que se levanta en estas oraciones-poemas. Los weychafe, los guerreros mapuche han señalado que las estrategias de recuperación de la tierra, como aquéllas que permitan recuperar y fortalecer la lengua y la cultura, deben seguir los principios del Az mapu y el itrofilmongen (Llaitul y Arrate, 2012). Az mapu, es el conjunto de leyes mapuche que rigen la vida de los distintos territorios, y el itrofillmongen, puede ser comprendido como la diversidad de formas de vida en equilibrio, equilibrio que permite la continuidad de la vida mapuche en el territorio. La organización de la vida mapuche y la organización del trabajo sigue estos dos ejes: por una parte, se organiza de manera comunitaria y, por otra, se enfoca no solo a producir, sino que también a recuperar los ecosistemas degradados por la invasión forestal. En la poesía de María Teresa Panchillo, el Trafkeyuwun, el trabajo comunitario mapuche en la tierra erosionada por la explotación forestal se evoca en el poema "Días y noches de trilla": "El polvo huele a trigo/ a pan./Goteando en sudor/ sobre mi cántaro sin agua/ (...)/ Verso por verso los granos/ Y la luna nueva/ parece una llama de fuego"(2006, 73). La defensa del agua, la denuncia del "pensamiento winka" que llama "cambio climático" a las consecuencias de la explotación de la naturaleza, despersonalizando y, por lo tanto, evadiendo la responsabilidad de las empresas implicadas, también es un tema recurrente en los poemas de Panchillo. La protección de los espacios de vida y la evocación permanente a la diversidad de plantas rituales y medicinales caracteriza a la poesía mapuche actual escrita por mujeres. Es a través de este conjunto de poéticas que la naturaleza vuelve a tener un espacio importante en la literatura. Pero ya no es la naturaleza que representa los ánimos del ser humano, no es proyección de alegría o de tristeza, de euforia o confusión, de placer o serenidad, no es refugio ni reducto romántico, tampoco paraíso imaginario donde desatar la abundancia del lenguaje poético barroco, no es siquiera revelación nostálgica del paraíso adánico. En la poesía mapuche la naturaleza es conocimiento, en ella está cifrada la ciencia mapuche: el mapuche kimün que permite el 
desarrollo con la naturaleza, no contra la naturaleza, del que nos habla Elicura Chihuailaf (1999). La ciencia mapuche de la que nos habla Paredes Pinda (2012).

La poesía mapuche ha tomado una función y un compromiso didáctico, al querer transmitir la importancia del conocimiento, valoración y cuidado de la naturaleza. Cada día que pasa hace que estas palabras tengan más sentido. Hace unos años atrás estas palabras podrían haber sido juzgadas de mapuchistas, hoy son equiparables al sentido común, y a la desesperación de quienes viven de manera más brutal las consecuencias del cambio climático que, como nos dice Panchillo, es causa de la deforestación y no culpa del "fenómeno del niño". Quienes viven en el campo, y sufren la sequía, viendo morir animales, bosques, viendo secarse los pozos, las vertientes, los ríos y estancarse en pantanos, naturales y artificiales, como los provocados por las centrales hidroeléctricas, los mapuche que porfían vivir en la tierra, resguardando el precario equilibrio que nos queda, pueden hacerse escuchar a través de esta poesía.

En la poesía mapuche actual habitan muchos de los seres maravillosos que forman parte del feyentun mapuche. En una serie de cuatro poemas breves que forman un solo conjunto (1993, 31), Maria Teresa Panchillo refiere a las Tuwin malen, uno de estos seres maravillosos de la cosmovisión mapuche que habitan los cuerpos de agua. En este poema, Tuwin malen se asocia a la conservación del itrovillmongen, que puede ser traducido como biodiversidad en equilibrio o equilibrio ecológico: en consecuencia, las Tuwin malen sostienen la vida de y en los cuerpos de agua. Panchillo nos recuerda que el desequilibrio ecológico ha sido provocado por la tala de árboles, por la expansión forestal descontrolada que degrada y extermina todo tipo de ecosistemas, especialmente en el territorio Nagche desde donde ella escribe. Actualmente el Estado de Chile no tiene una ley que proteja las riberas. No existe ningún tipo de regulación sobre la plantación y explotación a tala rasa que pudiera proteger lagunas, ríos y vertientes: “¿dónde habitarán mis tuwin malen?” Se pregunta Panchillo, quien se está refiriendo a sus dos hijas Ayenray y Janekew ¿en qué lugar del Wall mapu vivirán si ya el agua escasea por todas partes? Las Tuwin malen deben ser protegidas para que a su vez puedan seguir protegiendo la vida sobre la tierra, es esta una relación recíproca y, por lo tanto, desde el punto de vista mapuche, filial.

En el poema de Panchillo quién castigará la transgresión será Mevbeh, o Meulen, la manifestación de un remolino de viento, que toma forma de huracán para arrasar con la iniquidad de los hombres que no respetan el espacio sagrado de las aguas.

\section{TIERRA...MADRE}

Madre dicen que es la patria

La tierra dicen otros.

Pero madre que soy yo de dos hermosas TVWVN MABEH

De una patria y tierra por defender

\footnotetext{
${ }^{4}$ El pueblo mapuche habita un gran territorio que se denomina Wall Mapu, y en él se distinguen identidades territoriales asociadas a espacios bioculturales de relevancia: Nagche se refiere a las comunidades que habitan el territorio del valle, la tierra de abajo, y se distingue de Lafkenche, comunidades que coexiten junto al mar o Pewenche que habitan en la cordillera y viven del Pewen o Araucaria, árbol sagrado.
} 
Defender con honor que es deber...

\section{CÁNTAROS}

Cántaros de greda

Dos cántaros de mis sueños.

Aguas de vertientes

Vertientes en resistencias

Sin helechos los pajonales

Sin agua los esteros

¿Dónde habitarán mis TVWVN MALEH?

\section{GEHKO}

Fenómenos del niño le llaman

En wingkazugun.

El GEHKO fuera del mar

Enojado!...incontrolable.

Es un MWEBH nocturno

Huracán de invierno y verano

Haciendo justicia por su propia cuenta.

Pues sus hermanos ya no lo defienden

No lo entienden...

\section{KOMPLE MAPU}

Vendrán otros más fuertes

Por todas las tierras lejanas

Si continúan los daños ecológicos

Al planeta, al universo

Se cumplirán los sueños apocalípticos

De los ancianos sabios

GVNE MAPV saldrá de la tierra.

A hacer justicia.

Xayen, abril de 1998 (Panchillo, 1999, 31)

No hace falta aclarar el sentido ecocrítico de este poema tetralógico. Las palabras en mapudugun que no aparecen traducidas reafirman la sabiduría profunda de sus palabras: GEHKO es el/la denominación a la energía o principio energético del agua, también traducido como dueño (ngen) y protector del agua. KOMPLE: por todas partes, la vida sigue los mismos principios. Itrovilmonngen es la expresión mapuche de lo que la ciencia occidental denomina equilibrio ecológico, donde el agua es el elemento esencial en la regulación de dicho equilibrio, y que a la vez despliega un lenguaje propio, un Zugun, que dentro de la cosmovisión mapuche es posible comprender: 


\section{Zugun}

Aquí en la tierra

Hablamos todos

Las aves

Los animales

Las aguas.

Silba como el viento la culebra

Cuando viene el tiempo de lluvia

Y el silbar es su palabra.

Hay tiempo en que las ziukas

Hablan cantando al amanecer

CHOLLPIZ, COLLPIW!

Es el tiempo en que el MAPU brota

Rayo a rayo hacia el Sol...

Y hay que levantarse para saludarlo.

En el mismo tiempo de Reproducción

Las ranas cantan en coro de noche

Y la luna en menguante

Abre cascarones

En los escasos pajonales

Que van quedando

Hay otros que siempre hablan llorando

Como el MAYKOÑO

KUKU, KUKU EM...

Así es su idioma

Para conversar con su abuela paterna.

Los gakiñ dicen:

GAK GAK

Como recién nacidos llorando.

Daban ganas de escarbar

En el barro del pantano

Pero cuando se buscan

Se meten más dentro de la tierra

$\mathrm{O}$ se cambian de lugar.

Cuando niñas lo intentamos con mi hermana.

Y mis pewmas en la noche

Fueron solo pesadillas

SE ENOJARON...

ESO NO SE HACE!

Dijo mi madre.

Si se dejan ver

Sería PERIMONTUN. 
También hay animales

Que se ríen en su idioma

Como los perros

Ya caballos.

Mi Guardián salta y corre

Agarra su olla o un palo,

Se ríe,

Nos habla en su propio zugun

Cuando volvemos a casa

O si llega algún conocido.

Pero llora

Cuando ve al WEKUFV EN LAS NOCHES

Y cuando siente que viene el Nvyvn

Con grado a terremoto,

Entonces la gente se levanta y sale,

Se sienta en el suelo agarrada a la tierra

Le habla al temblor

IÑCHE TA FANEN,

FANEN

FANEN

FANEN

FANEN

FANEN

Yo soy pesada

Pesada

Pesada

Pesada

Pesada

Pesada.

¿Y el AGUA?

¡Oh, el agua!

Tiene un idioma único,

Habla cantadito,

Una melodía en las mañanas

Otra al medio día

Y en las tardes

Otra diferente

Hay que saber escucharla no más

Para saber que dice.

Así es la vida en mi MAPU

En la lógica occidental

Cualquiera me diría

"eso se llama sonido" 
Pero desde que somos CHE

Siempre fue así y será

ZVGUN

(Panchillo, 2010, 395-397).

Tal como ha señalado Panchillo en la configuración de su poética, la comunicación con la naturaleza a través de la comprensión de sus sonidos animales, vegetales, telúricos, es completamente posible y forma parte integral de su cultura y, por lo tanto, se expresa en el lenguaje poético del mapudungun, que a su vez se integra a los poemas escritos en español, a través de un proceso de traducción intercultural o de palabras mapuches yuxtapuestas a las palabras y versos en español. De esta manera María Teresa Panchillo logra vencer el pensamiento abismal, desarrollando una verdadera ecología de saberes (Santos, 2013), para poner en valor el conocimiento mapuche a través del mapudungun, exigiéndonos comprender una cosmovisión completamente diferente y fundamental para la vida de las comunidades mapuche, en su lucha por la justicia y por la autonomía territorial.

Esto implica que los lectores de Panchillo, deben hacer un esfuerzo intercultural, en el sentido de "que el otro puede tener razón", trascendiendo las lecturas bucólicas que sostienen la barrera del pensamiento abismal. De ese modo la imaginación poética pugna por desbordar las comprensiones propias de la modernidad, adoptando los lenguajes de la tierra que Panchillo invoca permanentemente a una reunión que sostiene su forma de vida en resistencia, y que le permiten avizorar una re-existencia en la ecología y la autonomía que demanda su lengua ancestral, ahora lengua poética intercultural.

\section{Referencias bibliográficas}

Bengoa, José (2004) La memoria olvidada: historia de los pueblos indígenas de Chile. Bengoa ( nter.) Santiago: Publicaciones del Bicentenario.

Betancour, Sonia; Geeregat, Orietta; García, Mabel. (2014). "Pueblo mapuche. Estrategias discursivo-comunicativas para un nuevo orden". En Signo y Pensamiento, Universidad Javeriana, Bogotá, Colombia: 62-77.

Briones, Claudia (2007) “Teorías performativas de la identidad y performatividad de las teorías". En Tabula Rasa, nº, enero-junio, pp. 55-83. Colombia: Universidad Colegio Mayor de Cundinamarca Bogotá.

Cabello, Cesar (2011) Las edades del Laberinto. Santiago, Chile: Ediciones Piedra de Sol.

Carrasco, Iván (1996) “Tensiones entre la intra y la interculturalidad en la poesía de E.Chihuailaf y L. Lienlaf”. En Lengua y Literatura mapuche nº7,vol I, Temuco: 27-39.

Correa, Molina \& Yáñez (2005) La Reforma Agraria y las tierras mapuches. Chile 1962-1975. Santiago de Chile: LOM Ediciones.

Chiguailaf, Elicura (1999). Recado confidencial a los chilenos. Santiago de Chile: LOM 
Correa \& Mella (2010) Las razones del illkun / enojo. Memoria, despojo y criminalización en el territorio mapuche de Malleco. Santiago de Chile: LOM Ediciones / Observatorio de Derechos de los Pueblos Indígenas.

Correa, Molina \& Yáñez (2005) La Reforma Agraria y las tierras mapuches. Chile 1962-1975. Santiago de Chile: LOM Ediciones.

Díaz, Aurelio (2006 [1907]). Parlamento de Coz Coz. Valdivia, Chile: Ediciones Ser indígena.

Figueroa, Noelia (2012). "De la subalternidad a la decolonialidad: notas para reflexionar sobre la alteridad del pueblo mapuche". Revista Argos, 29(57), 80-93. http://www.scielo.org.ve/scielo.php?script=sci_arttext\&pid=S0254$16372012000200005 \& \operatorname{lng}=$ es\&tlng=es. Revisado 10/12/2016

Figueroa, Noelia et al (2005) Aprendizajes para la Autogestión Territorial Mapuche: Experiencias de cinco organizaciones territoriales indígenas. Con la colaboración de representantes de la Asociación Nankuchew, la comunidad Felipe Punolef, la Asociación Pulafkenche la asociación Mapulahual. Concepción: Fonds Voor Ontwikkelingssamenwerking, FOS Bélgica \& Chile; I.S.B.N. 956-299-925-4.

Foerster, Rolf y Montecino, Sonia (1988) Organizaciones, líderes y contiendas mapuches (1900 1970). Santiago de Chile: CEDEM, Centro de Estudios de la Mujer.

Huenún, Jaime (2012) Reducciones. Santiago, Chile: Ediciones LOM.

Huirimilla, Paulo (2012) (editor, compilador) Weichapeyuchi ül:Cantos de guerrero. Antología de poesía política mapuche. Santiago, Chile: LOM Ediciones.

Llaitul y Arrate (2012) Weichan. Conversaciones con un weychafe en la prisión política. Santiago de Chile: Ceibo Ediciones.

Martínez, L. y Huenún, J. (2010) (Compiladores). Memoria Poética. Reescrituras de La Araucana. Santiago, Chile: Editorial Cuarto Propio.

Marimán, P. (2006) "Los mapuche antes de la conquista militar chileno-argentina”. En ¡...Escucha, winka...! Cuatro ensayos de Historia Nacional Mapuche y un epílogo sobre el futuro. Marimán, P; Caniuqueo, S; Millalén, J; Levil, R.: 53-126. Santiago, Chile: LOM Ediciones.

Panchillo, MaríaTeresa (1999). Amulepe tayiñ mogen/que nuestra vida continúe. Menorca, España: Comité de solidaritat amb els pobles d'América.

(2006) "María Teresa Panchillo". En Hilando en la memoria. 7 mujeres mapuche. Curriao, Huinao, Millapan, Manquepillan, Panchillo, Pinda, Rupailaf. Falabella, Ramay y Huinao, editoras. Santiago de Chile: Editorial Cuarto Propio.

(2009) "María Teresa Panchillo". En Hilando la memoria. Epu Rupa. 14 mujeres mapuche. Llanquipichun, Pulquillanca, Caniguan, Huequeman, Lancapichun, Guaquin, G. Huinao, Huenuñir, Paredes Pinda, Manquepilla, M.E. Huinao, Millapan, Panchillo, Rupailaf. Falabella, Huinao y Miranda Rupailaf editoras. Santiago de Chile: Editorial Cuarto Propio.

(2010) "Por causas del imperio". En Memoria poética. Reescrituras de la Araucana. Luz Ángela Martínez y Jaime Luis Huenún (compiladores), pp. 384-397. Santiago, Chile: Editorial Cuarto Propio. 
Paredes, Adriana (2012). Desgarro y florecimiento. Tesis para optar al grado de Doctor en Ciencias Humanas. Universidad de Valdivia. Tesis guiada por el profesor Iván Carrasco.

Santos, Boaventura de Sousa. 2013 [2010] Decolononizar el saber, reinventar el poder. Santiago de Chile-Uruguay: LOM Ediciones-TRILCE Ediciones.

Wenuan Escalona (2014) El Mapa Roto. Santiago, Chile: Del Aire Editores.

Wittig, Fernando (2006) La escritura en mapudungun: alfabetos en uso y nuevos escenarios. CISAI. Centro interdipartimentale di studi sull'america indigena. Università Degli Studi di Siena. Disponible en: http://www.unisi.it/cisai/arealingtesti.htm. Rescatado 15/01/17 